\title{
Sonic Others in Early Sound Studies and the Poetry of Edward Sapir A Salvage Operation
}

\author{
A. Elisabeth Reichel
}

\begin{abstract}
Characteristically, early research in soundscapes is suffused with a sense of sonophilia; that is, a fascination with auditory perception and sound as the inferiorized Other of sight. Soundscape scholars have thus often conceived of their work as a salvage operation, which is conducted to save what would otherwise be irretrievably lost to a visual regime. This moral impetus to redeem the "sonic Other" is at the center of this article, in which I investigate how notions of sonic alterity interweave with treatments of social and cultural alterity. To explore and interrogate the nexus of social, cultural, and sonic alterity for its political and ethical ramifications, I analyze the acoustics of the poetry of Edward Sapir. Sapir played a key role in the formation of cultural anthropology and the early development of linguistic anthropology. What is far less known is that he is also the author of over six hundred poems, some of which were published in such renowned magazines as Poetry and The Dial. Focusing on the poems "To a Street Violinist" and "Harvest," I probe the dynamics of an anthropo-literary project that sets out to salvage both non-visual sense perceptions and other-than-modern, Western ways of life.
\end{abstract}

Suggested Citation: Reichel, A. Elisabeth. "Sonic Others in Early Sound Studies and the Poetry of Edward Sapir: A Salvage Operation.” JAAAS: Journal of the Austrian Association for American Studies 1, no. 2 (2020): 303-315, DOl: 10.47060/jaaas.v1i2.57.

Keywords: Edward Sapir; R. Murray Schafer; early twentieth-century American anthropology; early twentieth-century American poetry; primitivism

Peer Review: This article was reviewed by the issue's guest editors and an external reviewer.

Copyright: (C) 2020 A. Elisabeth Reichel. This is an open-access article distributed under the terms of the Creative Commons Attribution 4.0 International License (CC-BY 4.O), which allows for the unrestricted use, distribution, and reproduction in any medium, provided the original author and source are credited. 


\title{
Sonic Others in Early Sound Studies and the Poetry of Edward Sapir
}

\section{A Salvage Operation}

\author{
A. Elisabeth Reichel
}

2

efore Franz Boas entered U.S.-American anthropology to become one of its key twentieth-century protagonists, he had written his habilitation thesis on Baffin Island in the Canadian Arctic and conducted geographic research on indigenous migrations. It was in the mid-1880s that his research interests then shifted toward anthropological questions and in particular linguistic anthropology. When analyzing the notes from his first field trip to British Columbia, a three-month stay in 1886, he noticed significant variations in the spelling of individual words at different points in time: What at one point had been transcribed as "Operníving" appeared to sound more like "Upernívik" at another and like "Uperdnívik" at yet a third point in time." Contrary to then commonly held views on "alternating sounds," the patterns that he recognized within these variations bore evidence of his own language's phonetics rather than that of the speech system under consideration. Faced with a serious challenge to the integrity of his data, Boas launched an intervention in contemporary debates whose wider implications would far exceed anthropological linguistics.

Boas's article "On Alternating Sounds," published in the American Anthropologist in 1889, posits that "a new sensation," such as hearing an unknown language, "is apperceived by means of similar sensations that form part of our knowledge," such as the sound of one's own language. ${ }^{2}$ After careful and rigorous analysis, incorporating evidence from psychophysics, linguistic psychology, and comparative philology-including his own fieldnotes-Boas concludes:

I maintain that there is no such phenomenon as ... alternating sounds ...; that alternating sounds are in reality alternating apperceptions of one and the same sound. A thorough study of all alleged alternating sounds ... will show that their existence may be explained by alternating apperceptions. 


\section{is}

A. Elisabeth Reichel

Moreover, if alternating sounds are in fact the result of the observer's own "alternating apperceptions," they cannot be understood as "a sign of primitiveness of the speech in which they are said to occur."3 Apart from a vexing methodological problem, Boas addressed in the process the prevailing sociocultural evolutionist interpretation, which read "alternating sounds" as inherent in the language under consideration and as "traces of the 'vague,' 'fluctuating,' and still tentative language of paleolithic man." As Brian Hochman notes, "The more consistent the phonetics of a language, the logic went, the higher the stage of its evolutionary maturity-the more advanced its place in the historical continuum from orality to literacy, savagery to civilization." ${ }^{5}$

By revealing his contemporaries' diagnosis of alternating sounds in primitive languages to be the result of their own alternating perceptions and their contingency on one's cultural background and linguistic knowledge, Boas addressed the Euro- and ethnocentrism that remain unchallenged in scholarship at that time; this scholarship is most typically credited with a foundational role in the field of sound studies, that is, R. Murray Schafer's World Soundscape Project, established at Simon Fraser University in the late 1960s, and in particular his 1977 monograph The Tuning of the World, which grew out of this project. Crucially, Schafer's early, characteristically sonophilic work in sound and soundscape studies involves distinctions between modes of sense perception as well as groups of people. ${ }^{6}$ It thus aligns people other than urban North Americans, on one level, with the sense of hearing per se and, on another, with sounds that are deemed pristine-only to ultimately assign them, on both these levels, to an earlier, premodern stage of human development. However, rather than offering a corrective and a reworking of its flawed premises, as other sound scholars have successfully done, ? I use Schafer's original conceptualization of the soundscape to show that it is precisely its allochronism on which the poetic soundscapes of early-twentieth-century American anthropologist Edward Sapir are based, as well.

Sapir was among the first of Boas's many students who went on to become influential anthropologists themselves. He remained the only Boasian, however, who continued and developed his teacher's strong early interest in linguistics-manifest in such writings as "On Alternating Sounds"-while this interest became less pronounced in Boas's own, later research. Thus, besides his work within the cultural pluralist and relativist paradigm that formed Boas's principal contribution to American anthropology, Sapir is primarily known today for his accomplishments in linguistics, most famously, as a pioneer of linguistic relativity and the teacher of Benjamin Lee Whorf. What is rarely acknowledged, however, is the fact that Sapir also wrote over five hundred poems, many of which were published in renowned magazines of the time, such as Poetry, The Dial, The New Republic, and The Nation. The other half, Sapir's unpublished poetry, remained in family possession until 2008 and are now held by the American Philosophical Society, which did not catalogue and fully process the 


\section{3}

Sonic Others in Early Sound Studies and the Poetry of Edward Sapir

\section{Edward Sapir Papers until 2018.}

It is this largely unexamined corpus of published and unpublished poetry written by one of the foremost twentieth-century American anthropologists that I would like to explore in the second part of this essay. More specifically, I probe the dynamics of a project that sets out to salvage both non-visual sense perceptions and ways of life that are not considered modern. Schafer's school of acoustic ecology as well as Sapir's literary acoustics are envisaged as an operation to salvage what would otherwise be lost to a predominantly ocular and cacophonous, modern sensescape. ${ }^{8} \mathrm{Mov}-$ ing from the urban soundscape of the poem "To a Street Violinist" (1917) to the rural sounds and silences of the poem "The Harvest" (1920), I argue that Sapir's poetry carries Schafer's anti-modern nostalgia for prelapsarian ways of sensing, projected onto people other than urban North Americans, to its logical conclusion-that is, a salvage operation that ends in silence.

In The Tuning of the World, R. Murray Schafer unfolds an argument that involves two sensory oppositions, the poles of each dispersed on a linearly progressing timeline: on the one hand, he reiterates the orality/literacy divide, a staple of debates that took place in both anthropology and communication theory in the second half of the twentieth century. Schafer posits that "in the West the ear gave way to the eye as the most important gatherer of information about the time of the Renaissance, with the development of the printing press and perspective painting." Hearing, in this narrative, is placed within an earlier, premodern time, which is regrettably lost. As Marshall McLuhan, the most notorious popularizer of orality-literacy theory, claimed in a Playboy interview, "Literacy propelled man from the tribe, gave him an eye for an ear and replaced his integral in-depth communal interplay with visual linear values and fragmented consciousness."

On the other hand, Schafer opens up a distinction between good and bad sounds, between sounds that "truly matter" and those that divert from them. Noting that "there are no earlids," Schafer contends that "of its own nature then, the ear demands that insouciant and distracting sounds would be stopped in order that it may concentrate on those which truly matter." "Again, the side with a positive value of a zerosum equation is situated in the past, as a line of progression-or rather, regression-is drawn:

The soundscape of the world is changing. Modern man is beginning to inhabit a world with an acoustic environment radically different from any he has hitherto known. These new sounds, which differ in quality and intensity from those of the past, have alerted many researchers to the dangers of an indiscriminate and imperialistic spread of more and larger sounds into every corner of man's life.... It would seem that the world soundscape has reached an apex of vulgarity in our time. ${ }^{12}$ 


\section{is}

A. Elisabeth Reichel

Schafer's work is suffused with a sense of nostalgia that conjures up a prelapsarian past to criticize the present sensory regime and its acoustic practices in order to correct what he perceives as a neglect of the acoustic in general and of sounds "that matter" in particular. Accordingly, Schafer devises a twofold salvage operation: it sets out to redeem our sense of hearing from ocularcentrism as well as save the last remaining pristine sounds before they fall prey to modern cacophony and "vulgarity."13

What is more, both these dimensions of Schafer's acoustic salvage work become imbricated with class and racial hierarchies, as temporal lines of progression are projected onto space. As with McLuhan in some of his most racially tinged moments, ${ }^{14}$ Schafer maps the evolution from orality to literacy, and the consequent shift from hearing to seeing that he posits, onto spatial distinctions in the present: "Before the days of writing, in the days of prophets and epics," he asserts, "the sense of hearing was more vital than the sense of sight. The word of God, the history of the tribe and all other important information was heard, not seen." Yet "in parts of the world," he adds, "the aural sense still tends to predominate."15 He goes on to quote psychiatrist John Colin Carothers on his claim that "rural Africans live largely in a world of sound-a world loaded with direct personal significance for the hearer-whereas the western European lives much more in a visual world which is on the whole indifferent to him.... Whereas for Europeans, in general, 'seeing is believing,' for rural Africans reality seems to reside far more in what is heard and what is said."16 By thus mapping evolutionary notions of the senses onto geographical space and associating "the western European" with sight and "rural Africa" with hearing in the process, Schafer places coexisting social and racial groups of people in different but sequentially related times: Africans come to live in the days "before... writing, ... the days of prophets and epics," while Europeans live in contemporary, modern times. ${ }^{17}$ This form of disenfranchisement is well known to anthropologists as "allochronism," a term coined by Johannes Fabian in Time and the Other: How Anthropology Makes Its Object (1983). In this landmark contribution to anthropology's Writing Culture debate and 1980s' crisis of representation, Fabian identifies an allochronistic treatment of its subjects of investigation, which denies their coevalness by placing them in the past as a core feature of the history of anthropology and one of the discipline's defining characteristics. ${ }^{18}$ It should have become clear by now, though, that what Fabian describes as an important strategy historically used by ethnographers to assert their power over people classified as "savage," "barbarian," and "primitive" is not limited to the disciplinary boundaries of anthropology. Early soundscape theory, too, denies the coevalness of certain groups of people by placing them in an earlier, presumably more acoustic time.

Schafer's temporally inflected binarism between good and bad sounds is also pro- 
jected onto spatial differences, thereby reinforcing familiar lines of class and racial discrimination. Sounds that are good and worthy of being salvaged frequently pertain to what Schafer terms a "hi-fi" soundscape, that is, a "portion of the sonic environment" that "possess[es] a favorable signal-to-noise ratio," and since "the country is generally more hi-fi than the city; night more than day; ancient times more than modern," countrypeople are moved metonymically into "darker," ancient, premodern times..$^{19}$ Apart from local and regional differences, Schafer asserts a broad historical transition from a rural, hi-fi to an urban, "lo-fi" world soundscape. However, to this universal shift, as to the presumed universal shift from hearing to seeing, he again adds some noteworthy present-day exceptions:

There are many towns still, the world over, where life moves uneventfully, almost by stealth. Poor towns are quieter than prosperous towns. I have visited towns in Burgenland (Austria) where the only sound at midday is the flapping of storks in their chimney nests, or dusty towns in Iran where the only motion is the occasional swaying walk of a woman carrying water while the children sit mutely in the streets. Peasants and tribesmen the world over participate in a vast sharing of silence..$^{20}$

$\mathrm{Hi}-\mathrm{fi}$ soundscapes, the remnants of a quieter, more idyllic time in this jeremiad, are thus inhabited today by "peasants and tribesmen" in the "poor towns" of Burgenland, Iran, and "the world over." In Schafer's early conception of soundscape studies, whose declared goal is to enhance the world soundscape by salvaging our sense of hearing and select sounds, people other than urban, middle-class North Americans thus serve as foils onto which acoustic desires are projected. Given that what is desired lies in the past, these groups of people are not only construed as essentially different in this way but also placed in an earlier, bygone stage of human development, a stage outside the purview of Schafer's own, modern salvage operation.

To be sure, the field of sound studies has come a long way since the first publication of Schafer's The Tuning of the World, with its current practitioners being often acutely aware of the intricate entanglements of ideas about soundscapes with class and racial ideologies. Historians of sound and hearing, in particular, have carefully delineated ideological constructions of sonic alterity in specific contexts and discursive fields. Mark M. Smith's Listening to Nineteenth-Century America (2001), for instance, has shown the reciprocal construction of a "sonic other" on the two opposing sectional sides of antebellum America: While the South conjured up a northern soundscape that resounded with the noises of excessive capitalism, industrialism, and urbanism, the North evoked a southern soundscape that echoed with the fearful silence of a tyrannical system based on slavery. ${ }^{21}$ Most recently, and with a focus on discourses in early-twentieth-century Britain, James G. Mansell's The Age of Noise in Britain: Hearing Modernity (2017) has examined claims to modern selfhood 


\section{is}

A. Elisabeth Reichel

and expert authority that instrumentalize notions of noise to carve out a powerful social position. Introducing this project to his readers, Mansell notes that the earliest sound studies theory from the 1970 s at times reproduces the patterns that he observes in British auditory culture between 1914 and $1945 .{ }^{22}$ He thus comes to suggest-tentatively and in conjunctive mood-what the first part of the present article has asserted with some certainty, namely that Schafer's approach "impl[ies] the categorization of sound as ideally premodern." Further, the persistent story of modernity's staunch ocularcentrism and its concomitant "nostalgia for a lost world of ... freedom from the insidious creep of scopic control" also comes with a strong tendency to construe hearing in itself "as un- or premodern," belonging to an earlier, past stage of human development. ${ }^{23}$

Having thus reinforced previous criticism of early sound and soundscape studies for their allochronist tendencies, my interest in the remaining portion of this essay lies with the literary imagination and acoustics of the Boasian cultural anthropologist Edward Sapir. While regularly recognized as one of the most influential anthropologists and linguists of the twentieth century, a critical assessment of Sapir the poet remains a research desideratum. "One thing we need about Sapir is a reappraisal of his verse," proclaims Alfred L. Kroeber, Boas's first doctoral student and first professor of anthropology at Berkeley. ${ }^{24}$ And Ruth Benedict, who also published poems in modernist little magazines while working under Boas at Columbia, admonishes, too, that "an appreciation of Edward Sapir is incomplete without mention of him as a poet." ${ }^{\prime 25}$ Despite such forceful advocates, analysis of Sapir's poetry remains to date mostly limited to biographical and intentionalist readings which reduce the texts to an outlet of personal expression and a conduit for private thoughts. Richard Handler has written a series of articles that position the poems, as well as Sapir's critical writing on music and literature, in relation to the author's anthropological work and in the context of early twentieth-century art movements. ${ }^{26}$ Yet while Handler argues for an understanding of Sapir's poetry as more than an anthropologist's "diversion," he nonetheless continues to subordinate Sapir's literary writing to his anthropological work. ${ }^{27}$ Handler's relegation of Sapir's poetry from "a body of material to be scrutinized on its own terms" to an "index" to Sapir's anthropology has been found by Brian Carpenter to be the long-standing approach among Sapir scholars. ${ }^{28}$

My present effort to fill this research lacuna proceeds from the observation that Sapir's poetry is characterized by a sustained interest in different soundscapes and the people who inhabit them. The poem "To a Street Violinist" (1917), for instance, portrays a street musician that is drowned out by the "hubbub" of an urban soundscape: 


\section{3}

Sonic Others in Early Sound Studies and the Poetry of Edward Sapir

\section{To a Street Violinist}

I've often seen you bow your fiddle--

I've never heard more than a jangling scrape;

The hubbub always hid your tune.

Your clothes are torn,

You are bent,

You seem intent

On your fiddling,

And your face is neither sad nor gay.

I wonder--are you blind?

No one listens--

You do not seem to mind.

No one stops to drop a cent

Into your cup--

You do not seem to mind.

I cannot hear your music,

And your fiddling is the saddest

I have seen. ${ }^{29}$

As in Schafer's The Tuning of the World six decades later, "To a Street Violinist" puts forward a critique of modern urban cacophony that enlists other people to serve as foils onto which auditory desires are grafted. The intimacy between the speaker and his subject of interest suggested by second-person address and direct questioning is merely imagined and otherwise frustrated by a spatial distance to the street violinist (note the title's more distant address). In this imagined encounter, the other appears "bent" and "seem[s] intent" on working hard to make a living while receiving no recognition whatsoever: "No one listens," "no one stops," and no one drops so much as a cent. However, the repetition of the devastating "No one" is countered in equal measure by the reiteration of "You do not seem to mind," which is attached to and demarcated by a dash from the lack of appreciation that it outweighs. We thus witness how the persona, when confronted with the "hubbub" of a modern urban soundscape, conjures up a sonic other that-much like Simmel's blasé metropolitan subject ${ }^{30}$-has learned to stay resolutely detached from and unaffected by the oppressive environment.

In the poem's final tercet, then, the persona amplifies the opposition between good and bad sounds, a violin playing versus metropolitan "hubbub," the second sensory dichotomy that is central to Schafer, namely, hearing versus seeing. Unable to "hear [the street violinist's] music" from a distance through the city's din, the persona is limited to sight and declares the musician's fiddling to be "the saddest / [he] 


\section{is}

A. Elisabeth Reichel

ha[s] seen." Interestingly, the modern primacy of sight that Schafer assumes is thus presented, not as its source, but as a necessary result of an excess of bad, "insouciant and distracting" sounds. ${ }^{31}$ This logic-that a profusion of bad sounds must entail a preference for sight-also explains the persona's bewilderment at the fiddler's disregard for the highly visible indifference of the passersby: "I wonder--are you blind?" Given the excessive noise to which they both are subjected, the persona fails to understand why the violinist does not use sight for orientation just as he does, save that the musician is blind.

In contrast to "To a Street Violinist" and its urban, "lo-fi" soundscape, the poem "The Harvest" (1920) stages an encounter which prominently features the voice of a farmer in what Schafer would classify as a "hi-fi" soundscape:

The Harvest

Pipe-smoke is floating over his slow speech.

I love this grizzled farmer's gentle voice; It hints to me, "I have known to walk and rejoice

In the corn, in the hay, where the sun and the sharp rain teach

By turns; and twelve moons and the weathers, 0 each

Has fingered my patient heart, like little boys

That fondle and batter their silent, submissive toys."

I love this voice and the pauses of broad reach

That space his words out like a peaceful village,

House-dotted on a prairie of full-ripe tillage,

And smoke-trails weave with the wind along to a bluer

Height.... We are sitting bent over embers; now fewer,

Lower, come words... There comes a snow-wind pillage

And the black earth is dead, but the harvest sure. ${ }^{32}$

Despite the prominence of the farmer's voice in this poem, the interlocutor serves again as a foil onto which the persona grafts his auditory desires, creating in the process a subject worthy of being salvaged from the vulgarity of the modern world's soundscape that both Schafer's Tuning of the World and Sapir's poetry diagnose. Yet even more, I argue, "The Harvest" is also a manifestation of the act of silencing that this operation implies by necessity. For one, while the "slow speech" of the farmer is quoted at great length, taking up five of the poem's fourteen lines, the persona does not engage with the words on a semantic level. The farmer's account of the harsh weather conditions that "fondle and batter" him like a "silent, submissive toy[]" is taken as a mere "hint[]" and reduced to a series of "gentle" sounds, which the persona proclaims to "love" twice in the two lines that bracket the account. The long vowels of "slow speech" help to evoke the soothing nature of this sound. However, just as much as the farmer's voice, the speaker loves "the pauses of broad reach," 
and it is these long silences that dominate the second half of the poem. As the voice slowly fades out, the fact that "fewer, / Lower, come words" is imitated-again by the use of onomatopoeia-through a paratactic syntax interspersed with ellipses. Thus, the poem's words, too, are "space[d]" out "like a peaceful village," creating an aesthetic experience for the reader of the soundscape described. Finally, the farmer's voice falls silent together with that of the persona as "a snow-wind pillage" leaves "the black earth ... dead, but the harvest sure."

The largely silent exchange that the poem thus portrays manifests a desire for a premodern, hi-fi soundscape that is not merely projected onto a locale but also onto its inhabitants, thereby rendering the "grizzled farmer" a pleasantly silent relic to be salvaged in written text. The farmer is silenced in at least three ways: first, by being used as a foil onto which the persona projects his own desires. ${ }^{33}$ Second, since the desire that the persona projects onto him is a desire for tranquility, silence is also the logical conclusion to which Sapir's-but also Schafer's-salvage operation must ultimately lead. In fact, the paradox of a project that has to "black out" the very people that it wants to save in order to be successful is captured in the final image of "The Harvest," the "snow-wind pillage" that renders the field "black" and "dead" "but the harvest sure." David Hendy has also recently expressed concern about Schafer's story "edging into slightly misanthropic territory, as if the world would be better if only the people in it disappeared." 34 However, what has been important for me here, too, is the distinction between different groups of people that this story involves, and which makes some people recede into the past while others-the moderns-are burdened with the task of preserving them.

The point on which I would like to conclude, though, is a different one. The salvage operation called for by both Sapir's poetry and Schafer's soundscape studies must necessarily end in silencing the sonic others that they set out to save, but not solely by projecting a desire for a soundscape that is largely silent onto them. Crucially, only by being perceived as endangered and on the brink of extinction do they first become a subject of interest to be salvaged from the ocularcentrism and cacophony of modernity. Their redemption, in other words, requires the moral impetus that the prospect of their loss generates. By presenting positive sounds and a sensitivity to the acoustic as vanishing remnants of an earlier time, then associating them with racial and class difference in the present, Schafer produces groups of people and sounds whose value is dependent on their imminent extinction. Similarly, the street musician in Sapir's "To a Street Violinist" becomes a subject worthy of being salvaged as he is drowned out by an urban cacophony and ignored by everyone except the speaker. In "The Harvest," in turn, the presence of the farmer is predicated on a "love" for the slowness and gentleness of the old, "grizzled" man's voice, a voice which is on the verge of falling silent and indeed dead by the end of the poem. 
It is one of the central ironies of both Sapir's and Schafer's antimodern salvage projects that they mourn the death of prelapsarian quietude at the same time as they take advantage of modernity's disruptive technologies, for instance, when travelling to remote locations to record otherwise inaccessible and yet "untouched" sounds. While these texts thus engage in a circular reasoning which contributes to the vanishing of its subject of interest only to rescue it from its deplorable fate with modern tools, they advance an understanding of the value of certain soundscapes and their inhabitants that is tied to a position of primordiality. Boas's "On Alternating Sounds," to return to the text with which I opened this article, forms an early critique of such arrangements of coexisting sounds and people on an evolutionary ladder from primitive past to modern present. While Sapir's poetry thus falls squarely within Schafer's cultural evolutionist conception of the world soundscape, as my analysis has shown, his anthropology and linguistics is much more closely aligned with Boas's position and, indeed, premised from the start on "On Alternating Sounds." A student of Germanic linguistics at Columbia University, Sapir submitted his master's thesis on Johann Gottfried Herder's Treatise on the Origin of Language (1772) in 1905. ${ }^{35}$ While some scholars have claimed that Sapir did not encounter Boas's work and enter anthropology until after receiving his master's degree, thus "perpetuat[ing a] mythical post-M.A. conversion experience,"36 the impact of Boas's "On Alternating Sounds" on Sapir's thesis cannot be denied. Sapir is quick to dismiss Herder's claim of a penchant for fluctuations in primitive languages through reference to "untrustworthy reports" and the example of the language of "the Eskimos," the very language family that prompted Boas to write "On Alternating Sounds":

The oft-asserted and oft-repeated statement of the incredibly rapid change of the languages of primitive tribes is founded chiefly on the untrustworthy reports of linguistically inefficient missionaries; many of the extreme statements formerly and even yet current are absurdly untrue. Indeed, the most startling cases of linguistic conservatism are found among certain primitive peoples, such as the Eskimos. ${ }^{37}$

In the same vein, Sapir also discards the other allochronisms that are implicated in Herder's theory of the origin of language: Herder's "enthusiastic speculation ... on the singing-speech of primitive man," in other words, his claim of an originally musical character of speech which may be found today in "the accents of many savage idioms" is discarded as "the wildest and most improbable fancy"; Herder's notion that the sense of hearing precedes language and reason is further taken to be, "at least questionable"; and, finally, his conceit that "the oriental often prefers to have recourse to the sense of hearing" fails to be convincing, too. ${ }^{38}$ Thus, a marked difference emerges between the approach that Sapir applies to the cross-cultural study of sound as a Boasian linguist and anthropologist, on the one hand, and the literary 


\section{5}

Sonic Others in Early Sound Studies and the Poetry of Edward Sapir

acoustics of his own writing as a poet on the other. While the former deconstructs the cultural evolutionist speculations of Europeans and North Americans caught up in a rapid process of industrialization and urbanization, his poetry is also rife with the nostalgia for quieter times that inspires these sonic imaginations. Sapir's literary soundscapes thus extend into the twentieth century the cultural evolutionism that had been characteristic of Boas's adversaries in the "alternating sounds" debate, and which will continue to inform Schafer's 1970 s school of soundscape studies.

\section{Notes}

1 Franz Boas, "On Alternating Sounds," American Anthropologist 2, no. 1 (1889): 51, DOI: 10.1525/aa.1889.2.1.02a00040.

2 Ibid., 50.

3 Ibid., 52.

4 George W. Stocking, Jr., "From Physics to Ethnology", in Race, Culture, and Evolution: Essays in the History of Anthropology, ed. George W. Stocking, Jr. (Chicago: University of Chicago Press, 1982), 157-59.

5 Brian Hochman, Savage Preservation: The Ethnographic Origins of Modern Media Technology (Minneapolis: University of Minnesota Press, 2014), 88-89.

6 Sonophilia is the fascination with hearing as the Other to the mode of sense perception that is presumed dominant, as, for instance, sight in twentieth-century orality-literacy theory. On sonophilia in the work of Sapir, see A. Elisabeth Reichel, "Sonophilia / Sonophobia: Sonic Others in the Poetry of Edward Sapir," in Literature, Ethics, Morality: American Studies Perspectives, ed. Ridvan Askin and Philipp Schweighauser (Tübingen: Gunter Narr Verlag, 2015), 215-29.

7 See, for example, Emily Thompson, The Soundscape of Modernity: Architectural Acoustics and the Culture of Listening in America, 1900-1933 (Cambridge, MA: MIT Press, 2002); Philipp Schweighauser, The Noises of American Literature, 1890-1985: Toward a History of Literary Acoustics (Gainesville: University Press of Florida, 2006); Karin Bijsterveld, Mechanical Sound: Technology, Culture and Public Problems of Noise in the Twentieth Century (Cambridge, MA: MIT Press, 2008); Carolyn Birdsall, Nazi Soundscapes: Sound, Technology and Urban Space in Germany, 1933-1945 (Amsterdam: Amsterdam University Press, 2012).

8 I borrow the term "literary acoustics" from Philipp Schweighauser. See Schweighauser, Noises of American Literature; Philipp Schweighauser, "Literary Acoustics," in Handbook of Intermediality: Literature-Image-Sound-Music, ed. Gabriele Rippl (Berlin: de Gruyter, 2015), 475-93.

9 R. Murray Schafer, The Soundscape: Our Sonic Environment and the Tuning of the World (Rochester, VT: Destiny Books, 1994), 10.

10 Marshall McLuhan, "Playboy Interview: A Candid Conversation with the High Priest of Popcult and Metaphysician of Media," interview by Eric Norden, in Essential McLuhan, ed. Eric McLuhan and Frank Zingrone (New York: Basic Books, 1995), 240.

11 Schafer, Soundscape, 11-12. 
A. Elisabeth Reichel

12 Ibid., 3. While focusing on The Tuning of the World in the present essay, I would like to point to Schafer's pamphlet The Book of Noise (1968), which puts this story of decline into even more dramatic words-indeed, nothing short of a battle cry: "There are some who still think the significant battles are being fought in faraway places. But today the significant battles are being fought in the very hearts of our cities. In an attempt to improve or even maintain the quality of our environment it will be necessary to take a strong stand against the problems brought about by the careless use of our technology, because the sounds of our tools and technology are the loudest sounds in our environment. And they are multiplying. The modern city has become a sonic battleground. Humanity is losing." R. Murray Schafer, The Book of Noise (Indian River, ON: Arcana Editions, 1998), 3.

13 Schafer, Soundscape, 12, 3.

14 See Jonathan Sterne, "The Theology of Sound: A Critique of Orality," Canadian Journal of Communication 36, no. 2 (2011): 219-20, DOI: 10.22230/cjc.2011v36n2a2223.

15 Schafer, Soundscape, 11.

16 John Colin Carothers, quoted in Schafer, Soundscape, 11.

17 Schafer, Soundscape, 11.

18 Johannes Fabian, Time and the Other: How Anthropology Makes Its Object (New York: Columbia University Press, 2014).

19 Schafer, Soundscape, 274, 43 (also 272), 43.

20 lbid., 52.

21 Mark M.Smith, Listening to Nineteenth-Century America (Chapel Hill: University of North Carolina Press, 2001).

22 James G. Mansell, The Age of Noise in Britain: Hearing Modernity (Urbana: University of Illinois Press, 2017).

23 Schafer, Soundscape, 10.

24 Alfred Louis Kroeber, "Reflections on Edward Sapir, Scholar and Man," in Edward Sapir: Critical Assessments of Leading Linguists, vol. 1, ed. E. F. K. Koerner (London: Routledge, 2007), 171.

25 Ruth Benedict, "Edward Sapir," in Edward Sapir: Critical Assessments of Leading Linguists, vol. 1, ed. E. F. K. Koerner (London: Routledge, 2007), 45.

26 Richard Handler, Critics against Culture: Anthropological Observers of Mass Society (Madison: University of Wisconsin Press, 2005), 73-122; Richard Handler, "Sapir's Poetic Experience," American Anthropologist 86, no. 2 (1984): 416-17, DOI: 10.1525/ aa.1984.86.2.02a00240; Richard Handler, "The Dainty and the Hungry Man: Literature and Anthropology in the Work of Edward Sapir," in Edward Sapir: Critical Assessments of Leading Linguists, vol. 3, ed. E. F. K. Koerner (London: Routledge, 2007), 289-311.

27 Richard Handler, "Introduction to Sections Four and Five: Edward Sapir's Aesthetic and Cultural Criticism," in Culture, ed. Regna Darnell, Richard Handler, and Judith T. Irvine (Berlin: Mouton de Gruyter, 1999), 731.

28 Brian Carpenter, "An Inner Striving”: An Overview of Edward Sapir's Poetry Papers," Paideuma 41 (2014): 202.

29 Edward Sapir, "To a Street Violinist," August 7, 1917, TS, Edward Sapir Papers, American 


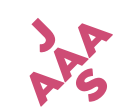

Sonic Others in Early Sound Studies and the Poetry of Edward Sapir

Philosophical Society, Philadelphia, PA.

30 Georg Simmel, "The Metropolis and Mental Life," in The Urban Sociology Reader, $2^{\text {nd }}$ ed., ed. Jan Lin and Christopher Mele (London: Routledge, 2013), 26-27.

31 Schafer, Soundscape, 12.

32 Edward Sapir, "The Harvest," The Nation (June 19, 1920), 825.

33 One could even go as far as to suggest that the phrase "It hints to me," by which the voice of the farmer is prefaced, indicates that what follows only exists in the imagination of the speaker. Several of my students have suggested such a reading. In the present essay, I take the passage set off by double quotation marks to comprise direct, quoted speech.

34 David Hendy, Noise: A Human History of Sound and Listening (London: Profile Books, 2013), xii.

35 Edward Sapir, “Herder's 'Ursprung der Sprache," Modern Philology 5, no. 1 (1907): 109-42.

36 Stephen O. Murray and Wayne Dynes, "Edward Sapir's Coursework in Linguistics and Anthropology," in Edward Sapir: Critical Assessments of Leading Linguists, vol. 1, ed. E. F. K. Koerner (London: Routledge, 2007), 109, no. 1.

37 Sapir, "Herder's 'Ursprung der Sprache," 134.

38 Ibid., 124-27.

\section{Acknowledgments}

I would like to thank Philipp Schweighauser and Alexandra Supper for their generous feedback on an earlier version of this essay. I am further indebted to the friendly support of Brian Carpenter, the curator in charge of the Edward Sapir Papers at the American Philosophical Society. Finally, a hearty thanks to the students who participated in my seminars "Writing Literature, Writing Culture" and "Of Anthropologists and Poets" for their valuable input during our classroom discussions.

\section{About the Author}

A. Elisabeth Reichel is Assistant Professor of American Studies ("Akademische Rätin") at the University of Osnabrück. She is the author of Writing Anthropologists, Sounding Primitives: The Poetry and Scholarship of Edward Sapir, Margaret Mead, and Ruth Benedict (University of Nebraska Press, 2021).

Contact: A. Elisabeth Reichel; University of Osnabrück; Department of English and American Studies; elisabeth.reichel@uni-osnabrueck.de. 